\title{
Epstein Barr Virus detection and latent membrane protein 1 in oral hairy leukoplakia in HIV + Venezuelan patients
}

\author{
Xiomara González ${ }^{1}$, María Correnti ${ }^{2}$, Helen Rivera ${ }^{3}$, Marianella Perrone ${ }^{4}$ \\ ${ }^{1}$ Graduate Student Stomatology Program \\ ${ }^{2}$ Associate Professor, Head of Molecular Genetic Laboratory.Instituto de Oncología y Hematología, Ministerio del Poder Popular \\ Para la Salud, Instituto de Investigaciones Odontológicas Dr. Raúl Vincentelli, Facultad de Odontología, Universidad Central de \\ Venezuela \\ ${ }^{3}$ Full Professor, Director Instituto de Investigaciones Odontológicas, Head of Oral Pathology Laboratory, Facultad de Odonto- \\ logía, Universidad Central de Venezuela \\ ${ }^{4}$ Full Professor. Instituto de Investigaciones Odontológicas Dr. Raúl Vincentelli, Universidad Central de Venezuela
}

Correspondence:

Laboratorio de Genética Molecular

Instituto de Oncología y Hematología

MPPS- 58-212-6050647

Caracas, Venezuela

mcorrentip@yahoo.com

Received: $11 / 12 / 2008$

Accepted: $28 / 11 / 2009$
González X, Correnti M, Rivera H, Perrone M. Epstein Barr Virus detection and latent membrane protein 1 in oral hairy leukoplakia in HIV+ Venezuelan patients. Med Oral Patol Oral Cir Bucal. 2010 Mar 1;15 (2):e297-302.

http://www.medicinaoral.com/medoralfree01/v15i2/medoralv15i2p297.pdf

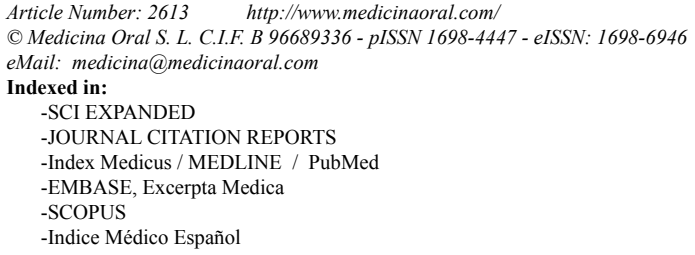

\begin{abstract}
Purpose: To determine the prevalence of Epstein Barr Virus (EBV) in oral hairy leukoplakia lesions (OHL) in HIV+ Venezuelan patients. Material and Method: In this case study, we evaluated $21 \mathrm{HIV}+$ adult patients with clinically present OHL lesions, 11 who were undergoing antiretroviral therapy, 10 who were not undergoing therapy and $10 \mathrm{HIV-negative} \mathrm{adult} \mathrm{patients} \mathrm{with} \mathrm{hyperkeratotic} \mathrm{oral} \mathrm{mucosal} \mathrm{lesions.} \mathrm{All} \mathrm{of} \mathrm{the} \mathrm{subjects} \mathrm{were} \mathrm{as-}$ sessed at the Infectious Disease Center, Faculty of Dentistry, Central University of Venezuela, and were clinically examined to detect oral mucosal lesions with the confirmed histopathologic diagnosis. Nested-PCR was used to determine the EBV infection and the latent membrane protein-1 (LMP-1) expression by immunohistochemistry. Results: Of the subjects, 16/21 (76\%) of the HIV+/AIDS patients tested positive for EBV, whereas 5/10 (50\%) of the HIV-negative subjects tested positive for EBV. Conclusions: In the present study, a higher EBV prevalence was observed in HIV-positive patients when compared to HIV-negative patients without oral hairy leukoplakia, confirming the etiologic role in this entity. The LMP-1 in OHL patients who were both HIV+ and EBV+ was highly expressed $(60 \%)$ at the epithelial basal cells. No association between the alcohol and tobacco consumption was observed among the EBV-positive cases.
\end{abstract}

Key words: Oral hairy leukoplakia, human immunodeficiency virus, Epstein Barr virus, latent membrane protein. 


\section{Introduction}

The oral lesions associated to human immunodeficiency virus infection represent an important problem in the $\mathrm{HIV}+$ population, being predictive of the disease progression (1). Several studies have been done to establish the prevalence of the oral lesions associated to the disease, related with age, gender, tobacco, CD4 cell count and viral load $(2,3)$.

Preliminary investigations conducted in Venezuela (4) demonstrated that oral candidiasis was the most frequent opportunistic infection, followed by oral hairy leukoplakia and melanic hiperpigmentation, observing a high viral load associated to these oral lesions presence but independently of the CD4+ count.

Oral hairy leukoplakia (OHL) is related to EBV infection characterized by a viral replication within the epithelium of the lateral border of the tongue (5). Clinically presents as a white oral lesion and has been considered as an early indicator of HIV infection as well as a progression marker of the disease. Therefore, it of outmost importance to establish an early diagnosis.

OHL has been mainly related to severe immunodeficiency similar to the HIV infection, malignant tumors and organ transplanted patients (7). However, OHL has also been reported in patients with moderate or minor immunodeficiency and immunocompetent individuals (8).

EBV is a member of the Herpesviridae family, gammaherpesviridae subfamily infecting lymphocytes and epithelial cells. Previous EBV seroprevalence studies have indicated that more than $90 \%$ of the world population has antibodies against EBV, being the etiologic factor in malignant diseases such as Burkitt's Lymphoma and Nasopharyngeal carcinoma, mainly characterized by EBV latent infection and cellular proliferation (5).

The clinical and histopathologic OHL features are not enough for the final diagnosis, the EBV presence is required to fulfill the diagnostic definitive criteria (9). The virus could be detected by LMP-1 expression using immunohistochemistry or using Nested PCR detecting the viral DNA (10).

The latent membrane protein 1 (LMP-1) is considered the principal EBV oncoprotein, its expression is required for the EBV latent infection and B cell transformation (10).

With the antiretroviral therapy use in HIV/AIDS, the opportunistic infections have declined due to the use of antiretroviral therapy leading to a better quality of patient life (11).

The aim of the present study was to determine the prevalence of Epstein Barr virus (EBV) in oral hairy leukoplakia lesions $(\mathrm{OHL})$ in $\mathrm{HIV}+$ venezuelan patients.

\section{Materials and Methods}

We evaluated in this cases study, $21 \mathrm{HIV}+$ adult patients with clinically present OHL lesions, 11 with antiretroviral therapy, 10 without therapy and 10 HIV negative adult patients with hiperkeratotic oral mucosal lesions. All of them were assessed at the Infectious Disease Center, Faculty of Dentistry, Central University of Venezuela and clinically examined to detect oral mucosal lesions present and establish the histopathologic diagnosis. Nested-PCR was used to determine the EBV infection and the LMP-1 expression by immunohistochemistry. In the present study, patiens with white oral lesions previously diagnosed as oral lichen planus were excluded.

Clinical evaluation was conducted by the same examiner, an oral medicine practitioner following the Clearinghouse criteria of diagnosis (12) data was collected in a chart designed for this purpose. All the included patients with clinically present oral white lesions followed the diagnostic criteria reported by Axell et al. (13) and all signed a written informed consent to participate in the study.

Incisional biopsies were taken from patients with oral lesions divided in two fragments, one for the histopathologic and immunohistochemical diagnosis and the other one was frozen in $-70^{\circ} \mathrm{C}$ for the molecular analysis by nested PCR. Prior to DNA extraction the samples were centrifugated to $100 \mathrm{x} \mathrm{g}, 10$ minutes $4^{\circ} \mathrm{C}$, the pellet was resuspended in $1 \mathrm{PBS} \mathrm{ml}$ and centrifugated to $1000 \mathrm{xg}$, by one minute.

Peripheral blood samples $(5 \mathrm{cc})$ were obtained from $\mathrm{HIV}+$ patients, posterior to the oral clinical examination to determine the cell count using flow citometry and the viral load by RT- PCR (Amplicor HIV-1 test TM kit, Roche), considering a low viral load between 401-5000 copies / mm3, moderate $5001-30.000$ copies / mm3 and high $>30.000$ copies $/ \mathrm{mm} 3$

\section{Nested PCR:}

We obtained DNA from fresh biopsy samples, resuspended in digested buffer and proteinase $\mathrm{K} 1000 \mu \mathrm{g} /$ $\mathrm{ml}$ and $100 \mu \mathrm{l}$ de buffer lysis (100 mM of Tris-HCl, $\mathrm{pH}$ 8 and $0,1 \%$ sarcosin) were incubated overnight. Posteriorly, inactivation of proteinase $\mathrm{K}$ was done at $95^{\circ}$ for $5 \mathrm{~min}$ and followed by phenol-chloroform extraction and ethanol precipitation). The pellet was resuspended in $100 \mu \mathrm{l}$ of TE buffer $(10 \mathrm{mM})$, Tris-HCl $0,1 \mathrm{M} \mathrm{pH} 7,4$; $0,1 \mathrm{mM}$ EDTA $\mathrm{pH} 8,0$ by $20 \mathrm{~h}$ at $37^{\circ} \mathrm{C}$. The samples were kept at $-20^{\circ} \mathrm{C}$. $5 \mu \mathrm{l}$ of aqueous phase were used for PCR. To increase the sensitivity of EBV detection, nested PCR assay were apply, using W1- W2 (W1: 5'CTA GGG GAG AAC GTG AA 3') and (W2: 5' CTG AAG GTG AAC CGC TTA CCA 3') as the outer and W3W4 as the inner EBV-primers (W3: 5' GGT ATC GGG CCA GAG GTA AGT 3'), and (W4: 5' GCT GGA CGA GGA CCC TTC TAC $3^{\prime}$ ). The inner primers amplify a 192-bp within the sequence amplified by the outer primers. $25-\mu 1$ reaction mixture consisted of $1 \mu \mathrm{M}$ of each 
primer, $1 \mu \mathrm{g}$ of the extracted sample, $1 \mathrm{X}$ Taq Buffer (100 mM Tris-HCl, pH 8.3, 500 mM KCl, 11 mM Mg$\mathrm{Cl} 2$ and $0.1 \%$ gelatin), $200 \mu \mathrm{M}$ of each dNTPs and 1 unit of Taq DNA Polymerase were used. Initial denaturation occurred at $94^{\circ} \mathrm{C}$ for $4 \mathrm{~min}$, followed by 30 cycles: $45 \mathrm{~s}$ at $92^{\circ} \mathrm{C}, 30 \mathrm{~s}$ at $66^{\circ} \mathrm{C}, 45 \mathrm{~s}$ at $72^{\circ} \mathrm{C}$. A final extension was done at $72^{\circ} \mathrm{C}$ for $5 \mathrm{~min}$. For negative control water replaced the DNA target. DNA samples were reamplified in a nested PCR using a W3- W4 primers. We used the same amplification parameters for 40 cycles, using a 2 $\mu \mathrm{L}$ template from the first step amplification products. Subsequently, $10 \mu \mathrm{l}$ of the PCR reaction mixture were electrophoresed in a 3\% agarose gel containing $0.5 \mu \mathrm{g} /$ $\mathrm{mL}$ ethidium bromide and visualized under an ultraviolet transilluminator. A positive sample was considered when a 192 bp band was observed corresponded to EBV amplification.

Expression of EBV LMP-1 by immunohistochemistry:

The EBV (lmp-1) expression was done by immunohistochemistry following the standarized protocol. $3 \mu$ sections were obtained from each paraffin block, deparaffinated and antigenically retrieved using tripsyn $37^{\circ} \mathrm{C}$ (30 minutes) and endogeneous peroxidase was blocked with methanol H202 (20 minutes).The sections were incubated with Anti EBV monoclonal antibody (LMP clone CS-1-4, Dako, USA), diluted 1:50 for 45 minutes. The envision detection system was used for 20 minutes using diaminobenzidine (DAKO) to visualize the reaction and counterstained with Meyer hematoxylin.

The statistical analysis was done using the SPSS (13.0 version) and the Chi Square non parametrical test.

\section{Results}

Twenty-one HIV + adult patients with OHL were evaluated, 20 were males (95\%) and only one female (5\%), between 21 and 60 years of age $(45.5 \pm 12.3)$. In addition, 10 patients HIV- with oral mucosal hyperkeratosis were studied, 6 of them were males $(60 \%)$ and 4 were females (40\%), age ranging between 21 and 70 years with an average (51.94 \pm 16.8$)$.

Regarding the sexual behavior in the HIV + group, there was a predilection in men who had sex with men 20/21 (95\%), and just one patient was heterosexual, while in the HIV - group all patients were heterosexual (Table 1a, 1b)

In relation with the anatomical location and the presence of OHL, we observed 9/21 (43\%) had lesions at left border of the tongue, 10/21 (47\%) in right lateral border of the tongue, $1 / 21$ in both lateral borders of the tongue and buccal mucosa respectively.

In the HIV- patients with oral hyperkeratosis, we observed the lesions at the buccal mucosa sulcus in 3/10 patients $(30 \%), 1 / 10$ cases at right side, $4 / 10(40 \%)$ in both sides and $2 / 10(20 \%)$ at buccal mucosa and the tongue.

Table 1a. Demographic distribution of HIV (+) patients with oral hairy leukoplakia (OHL).

\begin{tabular}{|c|c|c|c|c|c|c|c|c|}
\hline Patients & Gender & Age (years) & $\begin{array}{l}\text { Sexual } \\
\text { Behavior }\end{array}$ & $\begin{array}{c}\text { Anatomical } \\
\text { Location }\end{array}$ & $\begin{array}{c}\text { EBV } \\
\text { Detection by } \\
\text { PCR }\end{array}$ & $\begin{array}{c}\text { Antirretroviral } \\
\text { Therapy }\end{array}$ & Smoking & Alcohol \\
\hline 1 & Male & 55 & MSM & Left & Negative & No & Yes & Yes \\
\hline 2 & Male & 48 & MSM & Right & Positive & Yes & Yes & No \\
\hline 3 & Male & 39 & MSM & Left & Positive & Yes & Yes & Yes \\
\hline 4 & Male & 49 & MSM & Left & Negative & Yes & Yes & No \\
\hline 5 & Male & 44 & MSM & Right & Positive & No & Yes & No \\
\hline 6 & Female & 42 & Heterosexual & Right & Positive & Yes & No & No \\
\hline 7 & Male & 40 & MSM & Left & Positive & No & No & No \\
\hline 8 & Male & 42 & MSM & Left & Positive & Yes & No & No \\
\hline 9 & Male & 57 & MSM & Left & Positive & Yes & Yes & No \\
\hline 10 & Male & 36 & MSM & Both & Positive & No & Yes & Yes \\
\hline 11 & Male & 60 & MSM & Right & Negative & No & Yes & No \\
\hline 12 & Male & 47 & MSM & Right & Negative & Yes & No & No \\
\hline 13 & Male & 30 & MSM & Right & Positive & No & No & No \\
\hline 14 & Male & 21 & MSM & Right & Positive & No & Yes & Yes \\
\hline 15 & Male & 29 & MSM & Right & Positive & No & No & No \\
\hline 16 & Male & 32 & MSM & Left & Negative & Yes & Yes & Yes \\
\hline 17 & Male & 44 & MSM & Right & Positive & Yes & No & No \\
\hline 18 & Male & 26 & MSM & Oral Mucosa & Positive & No & No & No \\
\hline 19 & Male & 40 & MSM & Right & Positive & Yes & Yes & Yes \\
\hline 20 & Male & 42 & MSM & Left & Positive & No & No & No \\
\hline 21 & Male & 35 & MSM & Left & Positive & Yes & No & No \\
\hline
\end{tabular}

PCR: Polymerase Chain Reaction EBV: Epstein Barr Virus. 
Table 1b. Demographic distribution of HIV (-) patients with hyperkeratotic oral lesiones.

\begin{tabular}{|c|c|c|c|c|c|c|c|}
\hline Patients & Gender & Age (years) & $\begin{array}{c}\text { Sexual } \\
\text { Behavior }\end{array}$ & $\begin{array}{c}\text { Anatomical } \\
\text { Location }\end{array}$ & $\begin{array}{c}\text { EBV } \\
\text { detection by } \\
\text { PCR }\end{array}$ & Smoking & Alcohol \\
\hline 1 & Female & 70 & Heterosexual & Right Border & Positive & Yes & Yes \\
\hline 2 & Male & 45 & Heterosexual & Both & Negative & Yes & Yes \\
\hline 3 & Male & 32 & Heterosexual & Left Border & Negative & Yes & Yes \\
\hline 4 & Female & 55 & Heterosexual & Both & Negative & No & No \\
\hline 5 & Female & 49 & Heterosexual & Both & Positive & Yes & No \\
\hline 6 & Male & 53 & Heterosexual & $\begin{array}{c}\text { Mucosa and } \\
\text { Tongue }\end{array}$ & Negative & Yes & No \\
\hline 7 & Male & 64 & Heterosexual & $\begin{array}{c}\text { Mucosa and } \\
\text { Tongue }\end{array}$ & Negative & Yes & No \\
\hline 8 & Male & 56 & Heterosexual & Both & Positive & Yes & Yes \\
\hline 9 & Female & 21 & Heterosexual & Left Border & Positive & No & No \\
\hline 10 & Male & 27 & Heterosexual & Left Border & Positive & Yes & No \\
\hline
\end{tabular}

PCR: Polymerase Chain Reaction EBV: Epstein Barr Virus.

The clinical diagnosis of OHL in HIV+was confirmed by histopathology observing marked parakeratosis, corrugated lining epithelium, acanthosis and the spinous cells with a clear cytoplasm and ballooning (Fig. 1).

In the HIV-group with hyperatotic lesions, only one case presented orthokeratosis, acanthosis and Severe epithelial dysplasia, one was diagnosed as oral lichen planus and eight were orthokeratosis, parakeratosis and acanthosis compatible with frictional keratosis.

The EBV genome was detected in 16/21 (76\%) of the HIV+ patients with OHL and in 5/10 (50\%) of the HIVpatients with hyperkeratotic lesions. Statistical significant differences were noted in both groups $(\mathrm{p}<0.05)$.

Regarding the antiretroviral therapy, $8 / 21$ (38\%) of the $\mathrm{EBV}+$ patients were under treatment, similar number (38\%) were EBV+ without therapy, while in the EBVcases, $2 / 21$ were not under therapy and 3/21 were under treatment.

Related to the habits, 11/21 EBV + patients were tobacco users and 10/21 were non smokers, however in the EBV- /HIV- 8/10 (80\%) were smokers and 2/10 (2\%) were non smokers. These results were statistical significant $(\mathrm{p}<0.05)$. In addition, the HIV+ patients $6 / 21(29 \%)$ were alcohol users and 15/21 (71\%) were non consumers, while in the HIV- patients, 4/10 (40\%) consumed alcohol and 6/10 (60\%) were not.

Regarding the presence of OHL /VEB + patients, we found 14/21 (66\%) of them presented a viral load $<400.000$ copies RNA / $\mathrm{ml}$ while only $2 / 21$ (10\%) presented high viral load $>400.000$ copies RNA $/ \mathrm{ml}$. The EBV-/OHL patients, 5/21 (24\%) had low viral load.

According to CD4+ T cell count in OHL/EBV+, we evidenced that $5 / 21(24 \%)$ had a cell count between 100 300 cells/ mm 3 , 4/21 (19\%) 301-500 cells/ mm3, 4/21 (19\%) $501-700$ cells $/ \mathrm{mm}^{3}$ and $3 / 21701-900$ cells $/ \mathrm{mm}^{3}$. When analyzing the OHL / EBV- cases, we determined that $3 / 21(14 \%)$ had a CD4+ T cell count ranging from $100-300 \mathrm{cells} / \mathrm{mm}^{3}$ and $1 / 21(5 \%)$ presented $301-500$ and other 500-701 cells/ $\mathrm{mm}^{3}$.

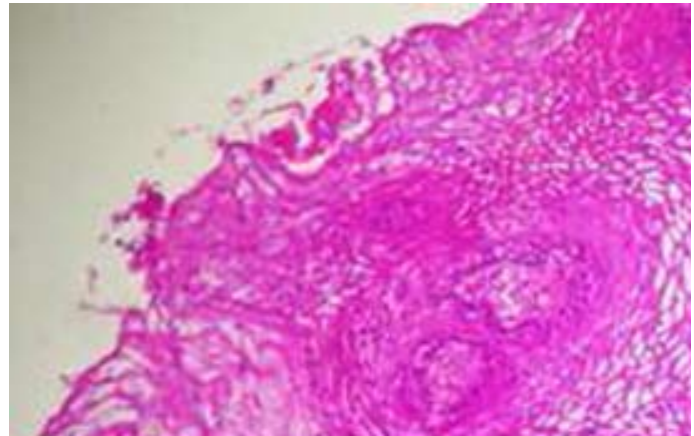

Fig. 1. Histopatologic aspect of oral hairy leukoplakia in HIV+ patients. HE X40.

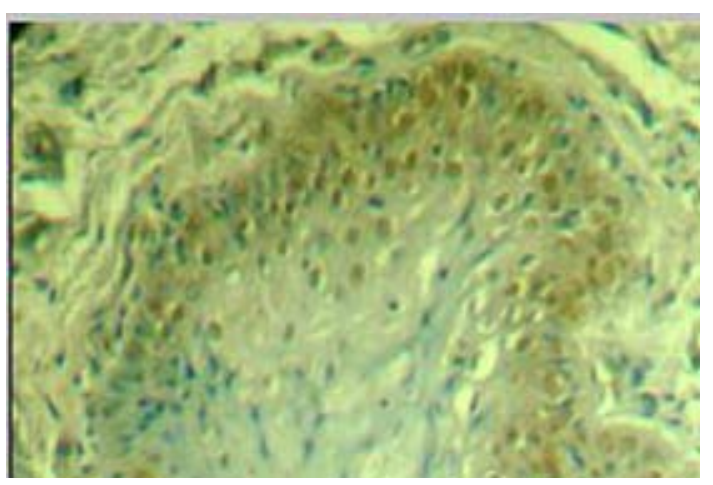

Fig. 2. EBV latent membrane protein -1 expression in oral hairy leukoplakia. X40. Note the high immunoreactivity in basal cells.

The EBV lmp-1 expression demonstrated nuclear positivity in 13/ $21(62 \%)$ of the cases. The immunolocalization was in the keratinocytes in 2/13 (15\%) and in $11 / 13(84.6 \%)$ in the basal cell layer. Additionally, 4/13 evidenced immunopositivity in the spinous cell layer. The intensity of the immunoreaction was low in $14 \%$, moderate in $29 \%$ and strong in $19 \%$ of the cases (Fig. 2). The extension of the immunostaining was 30-60 positive cells (19\%) and 60-100 (33\%) of the cases. 


\section{Discussion}

OHL represents a relatively frequent condition among $\mathrm{HIV}+$ patients associated with EBV infection. Its occurrence has a prognostic value, therefore it is considered an immunodeficiency marker especially in HIV $(+)$ with $10 \%$ of the individuals presenting AIDS at the moment of the diagnosis and $20 \%$ could developed it in the following eight months.

Previous studies have documented the OHL presence in moderate or mild immunodeficiency as well as in immunocompetent, in pregnant women and in diabetes mellitus patients (8). Additionally a positive correlation exits between the OHL prevalence and decrease of the CD4 T cell count (12\%).

In the present investigation, we detected the EBV $1 \mathrm{mp} 1$ expression in OHL in a group of HIV + and HIV - venezuelan patients.

The distribution of the studied population according to gender and age group demonstrated a $95 \%$ of the OHL/ $\mathrm{HIV}+$ corresponded to males while a $5 \%$ were females, between 21 and 60 years. These results are in contrast to other investigations (16) where females were more affected and in agreement with other authors reporting OHL was predominantly in males (17). These higher prevalence in males could be due to the sexual behavior, men who had sex with men that represents $95 \%$ in the present study in concordance with other reports (16). Regarding the distribution of OHL according to age we observed a similar range between HIV+ and HIV- patients.

The OHL clinical features in the present work are similar to previous reports from the literature, with white non removable lesions located at the lateral borders of the tongue, with unilateral or bilateral presentation, with a corrugated smooth or hairy surface. OHL usually appears in $\mathrm{HIV}+$ patients with severe immunodeficiency (18).

The most frequent OHL anatomical location is lateral borders of the tongue, however eventually could appear at ventral aspect of the tongue, floor of the mouth, soft palate and buccal mucosa (19), in agreement with the present study results where $5 \%$ of the evaluated patients presented the entity at right or left buccal mucosa.

In the present investigation we detected a high percentage of EBV positive patients (76\%) by nested PCR, in agreement with other studies demonstrating EBV in OHL (8).

Several studies have indicated that OHL/EBV is determined by the expression of multiple viral genetic products leading to infection and subsequent cell transformation, therefore contributing to the pathogenesis. The OHL spinous cell layer expressed viral latent and lytic proteins with a critical role in the development of the lesion (19).

In contrast to herpesviruses where a fulminant replica- tion occurs resulting in cellular lysis and ulcer formation, EBV/OHL may cause acanthosis probably induced by cellular proliferation to reassure the cell survillance within the lesion. These transforming proteins originated an optimal environment for viral replication and the subsequent cell infection (19). Recently, Bagan et al. (20) reported the EBV infection in oral squamous cell carcinoma and verrucous proliferative leukoplakia.

The molecular diagnosis using nested PCR is of highly sensitivity and specificity to detect low number of viral particles, that probably is the existent condition in this disease.

According to antiretroviral therapy in HIV+ patients, some authors have reported that it could not influence the disappareance of the disease (11), concordant with the present investigation results with a $38 \%$ of the EBV positive patients under therapy. It is noteworthy that these patients were under simple antiretroviral treatment and a $38 \%$ were not under therapy indicating that the treatment did not influence the appearance of the lesion.

In the present study, there was not association between tobacco use and the presence of OHL. However, there are studies indicating a positive relation among smokers and OHL (2). On the other hand, in the case of HIV-, the majority were smokers. Alcohol use was not associated to OHL in the present investigation.

In relation to viral load and EBV, our results demonstrated that a $66 \%$ of the EBV + individuals have a low viral load and $24 \%$ of EBV- presented a high viral load, concluding that there was not relation between viral load of the patient and EBV infection. Similar results were observed with the CD4+ T cell count in the HIV+/ OHL, where no association was observed.

The EBV lmp 1 in HIV+/EBV+/OHL patients was highly expressed (84.6\%) especially at the basal cells. In a preliminary study conducted in Venezuela, EBV lmpl was detected in all HIV+ patients with the diagnosis of diffuse lymphocytic infiltrative syndrome (DILS) in minor salivary glands (10) where EBV positivity was marked in contrast to cytomegalovirus expression. The differences of the $1 \mathrm{mp} 1$ expression in both studies could be due to the viral replication localization. In $\mathrm{OHl}$ it was observed at the epithelial basal cell while in the DILS was prominent at ductal epithelial cells.

\section{References}

1. Ceballos-Salobreña A, Aguirre-Urizar JM, Bagan-Sebastian JV. Oral manifestations associated with human immunodeficiency virus infection in a Spanish population. J Oral Pathol Med. 1996;25:523-6.

2. Lourenço AG, Figueiredo LT. Oral lesions in HIV infected individuals from Ribeirão Preto, Brazil. Med Oral Patol Oral Cir Bucal. 2008;13:E281-6.

3. Adedigba MA, Ogunbodede EO, Jeboda SO, Naidoo S. Patterns of oral manifestation of HIV/AIDS among 225 Nigerian patients. Oral Dis. 2008; $14: 341-6$. 
4. Bravo IM, Correnti M, Escalona L, Perrone M, Brito A, Tovar V, et al. Prevalence of oral lesions in HIV patients related to CD4 cell count and viral load in a Venezuelan population. Med Oral Patol Oral Cir Bucal. 2006;11:E33-9.

5. Young LS, Rickinson AB. Epstein-Barr virus: 40 years on. Nat Rev Cancer. 2004;4:757-68.

6. Greenspan JS, De Souza YG, Regezi JA, Daniels TE, Greenspan D, MacPhail LA, et al. Comparison of cytopathic changes in oral hairy leukoplakia with in situ hybridization for EBV DNA. Oral Dis. 1998;4:95-9.

7. Casiglia J, Woo SB. Oral hairy leukoplakia as an early indicator of Epstein-Barr virus-associated post-transplant lymphoproliferative disorder. J Oral Maxillofac Surg. 2002;60:948-50.

8. Milagres A, Dias EP, Tavares Ddos S, Cavalcante RM, Dantas VA, De Oliveira SP, et al. Prevalence of oral hairy leukoplakia and epithelial infection by Epstein-Barr virus in pregnant women and diabetes mellitus patients--cytopathologic and molecular study. Mem Inst Oswaldo Cruz. 2007;102:159-64.

9. Scully C, Porter SR, Di Alberti L, Jalal M, Maitland N. Detection of Epstein-Barr virus in oral scrapes in HIV infection, in hairy leukoplakia, and in healthy non-HIV-infected people. J Oral Pathol Med. 1998;27:480-2.

10. Rivera H, Nikitakis NG, Castillo S, Siavash H, Papadimitriou JC, Sauk JJ. Histopathological analysis and demonstration of EBV and HIV p-24 antigen but not CMV expression in labial minor salivary glands of HIV patients affected by diffuse infiltrative lymphocytosis syndrome. J Oral Pathol Med. 2003;32:431-7.

11. Aquino-García SI, Rivas MA, Ceballos-Salobreña A, Acosta-Gio AE, Gaitán-Cepeda LA. Short communication: oral lesions in HIV/ AIDS patients undergoing HAART including efavirenz. AIDS Res Hum Retroviruses. 2008;24:815-20.

12. No authors. Classification and diagnostic criteria for oral lesions in HIV infection. EC-Clearinghouse on Oral Problems Related to HIV Infection and WHO Collaborating Centre on Oral Manifestations of the Immunodeficiency Virus. J Oral Pathol Med. 1993;22:289-91. 13. Axéll T, Pindborg JJ, Smith CJ, Van der Waal I. Oral white lesions with special reference to precancerous and tobacco- related lesions: conclusions of an international symposium held in Uppsala, Sweden, May 18-21 1994. International Collaborative Group on Oral White Lesions. J Oral Pathol Med. 1996;25:49-54.

14. Greenspan D, Gange SJ, Phelan JA, Navazesh M, Alves ME, MacPhail LA, et al. Incidence of oral lesions in HIV-1-infected women: reduction with HAART. J Dent Res. 2004;83:145-50.

15. Patton LL. Sensitivity, specificity, and positive predictive value of oral opportunistic infections in adults with HIV/AIDS as markers of immune suppression and viral burden. Oral Surg Oral Med Oral Pathol Oral Radiol Endod. 2000;90:182-8.

16. Campisi G, Margiotta V. Oral mucosal lesions and risk habits among men in an Italian study population. J Oral Pathol Med. 2001;30:22-8.

17. Khongkunthian P, Grote M, Isaratanan W, Plyaworawong S, Reichart PA. Oral manifestations in HIV-positive adults from Northern Thailand. J Oral Pathol Med. 2001;30:220-3.

18. Greenspan JS, Greenspan D. Oral hairy leukoplakia: diagnosis and management. Oral Surg Oral Med Oral Pathol. 1989;67:396403.

19. Webster-Cyriaque J, Middeldorp J, Raab-Traub N. Hairy leukoplakia: an unusual combination of transforming and permissive Epstein-Barr virus infections. J Virol. 2000;74:7610-8

20. Bagan JV, Jiménez Y, Murillo J, Poveda R, Díaz JM, Gavaldá C, et al. Epstein-Barr virus in oral proliferative verrucous leukoplakia and squamous cell carcinoma: A preliminary study. Med Oral Patol Oral Cir Bucal. 2008;13:E110-3

\section{Acknowledgments}

This study was supported by FONACIT grant number 2005000408 and CDCH UCV PG 10-006522-2006 